\title{
Relationship Between Everyday Health Information Literacy and Attitudes Towards Mobile Technology Among Older People
}

\author{
Heidi Enwald ${ }^{1,2,3}$, Noora Hirvonen ${ }^{1,2,3}$, Maarit Kangas ${ }^{4}$, Niina Keränen ${ }^{4}$, Timo \\ Jämsä $^{4,3}$, Isto Huvila ${ }^{2}$, and Raija Korpelainen ${ }^{5,6,3}$ \\ Information Studies, University of Oulu, Oulu, Finland \\ \{heidi.enwald, noora.hirvonen\} eoulu.fi \\ ${ }^{2}$ Information Studies, Åbo Akademi University, Turku, Finland \\ isto.huviladabo.fi
}

${ }^{3}$ Medical Research Center Oulu, University of Oulu and Oulu University Hospital,

Oulu, Finland, Medical Imaging, Physics and Technology, University of Oulu, Oulu, Finland

\{maarit.kangas, niina.s.keranen, timo.jamsa\}@oulu.fi

${ }^{5}$ Oulu Deaconess Institute, Department of Sports and Exercise Medicine; ${ }^{6}$ Centre for

Life Course Epidemiology and Systems Medicine, University of Oulu, Oulu, Finland raija.korpelainen@odl.fi

\begin{abstract}
In order to benefit from advanced mobile information technology (AMIT) in e-health services, people need competencies in finding, evaluating, and understanding health-related information in varying everyday life situations, that is, everyday health information literacy (EHIL). This study focused on the relationship between EHIL and AMIT use and attitudes towards it among older adults. A paper questionnaire was posted to a random sample of 1,500 home dwelling subjects aged 65 or more living in Northern Finland. A variety of themes were addressed in the questionnaire including a 4-item version of an EHIL screening tool. The response rate was 61 percent $(n=918)$. Older adults with negative attitudes towards or having less experience with mobile information technology were likely to have poor self-estimated EHIL skills. Older people are at risk of marginalization in regard to m-services, and these results should be utilized by decision-makers and software designers in digitalization of services.
\end{abstract}

Keywords: Health information literacy, use of technology, mobile technology, ehealth, older adults.

\section{Introduction}


At present, technology use is often seen as a necessary prerequisite for older people to be integrated into society and also a factor that relates to active and successful aging. Older people may already be active users of the Internet and computers (seen in this paper as "traditional" information technology) but still may be reluctant to use advanced mobile information technology (AMIT) such as smart phones and tablet computers.

Many people between the ages of 60 to 80 are still generally healthy and fit. They want to maintain a high quality of life as long as possible. Their information and service needs differ from those with serious health problems. Individuals are expected to be involved in various aspects of health decision-making [1]. Nowadays, participation also often requires use of advanced information technology. Furthermore, effective participation and use of these kinds of new services require knowledge, skills, and abilities that relate to health information literacy [2].

The aim of this study was to investigate the relationship between everyday health information literacy and the opinions and use of advanced mobile information technology among older people. The research questions were as follows:

How does everyday health information literacy relate to

1) use of "traditional" information technology,

2) use of advanced mobile information technology, and

3) opinions about advanced mobile information technology among older people?

This study is a part of the Gamified Services for Elderly (GASEL) project that examined the requirements for tailored and gamified e-health services in promoting wellbeing and health of older adults $[3,4,5]$.

\section{Background}

\subsection{Older Adults as Users of Information Technology}

Aging populations, age related digital divide, and e-inclusion are fundamental European-wide challenges [6]. In 2016, the Council of European Union [7] published a press release concerning the accessibility of online public services, e.g., the websites and apps of public administrations, hospitals, courts, and other public sector bodies. The findings of Hill, Betts, and Gardner [8] support evidence of a "gray" digital divide that is not only caused by lack of access (first level digital divide) but by lack of use (second level digital divide). At the same time, older adults have been the fastest growing computer and Internet user group [9]. In Finland, elderly people are relatively techsavvy as 74 percent of people aged 65 to 74 and 31 percent of those aged 75 to 89 had used the Internet in the past three months in 2016. Of those aged 65 to 74 years old, 23 percent and 8 percent from the older age group had reserved a doctor's appointment online [10].

In recent reports of the GASEL project, it was noted that most of the older people who had used tablets or smart phones had not encountered any major difficulties in their use. Men and those under 70 years old were the most positive in their opinions about mobile information technology [5]. Older adults' frailty and pre-frailty were 
independently related to the nonuse of AMIT. The frail and pre-frail nonusers also held the most negative opinions on the usefulness or usability of this kind of technology [4].

\subsection{The Concept of Health Information Literacy}

Health information literacy can be seen as information literacy in the context of health or as a combination of the concepts of health literacy (HL) and information literacy $[11,12]$. While the concept of HL, mainly used in health sciences, is usually used to refer to the basic skills people need to be able to function in health care settings, HIL is focused on higher level cognitive abilities to find, evaluate, and understand health information also in everyday life situations. The Medical Library Association (MLA) [12] defines HIL as 'the set of abilities needed to recognize a health information need, identify likely information sources and use them to retrieve relevant information, assess the quality of the information and its applicability to a specific situation, and analyze, understand, and use the information to make good health decisions'.

Based on an operationalization of the MLA's definition of HIL, Niemelä et al. [11] designed a 10-item survey aiming at identifying differences in individuals' everyday HIL (EHIL). Their aim was to develop a simple and practical screening tool that could be used to detect individuals who would benefit from HIL counseling. Hirvonen et al. [13] found that EHIL scores were associated with socio-demographic characteristics as well as health behavior and physical health among young Finnish men. When young men were compared to adults with increased risk for metabolic syndrome, the latter seemed to value health information more but also had more difficulties in knowing who to believe in health issues and in understanding health-related terminology [14].

Niemelä et al. [11] identified three independent factors of EHIL: motivation of finding health information, confidence in one's ability to find, understand and use health information, and evaluation of health information. Furthermore, an item on the ability to understand terminology in health contexts was considered to be 'a fundamental HIL statement' and was analyzed separately. The three-factor structure has been confirmed in subsequent studies [16]. Based on this factor analysis, a shorter version of the tool with one statement representing each factor (motivation, evaluation, confidence, terminology) was proposed [11].

\subsection{Older Adults' Health information Literacy and Information Technology Use}

The importance of HL and HIL becomes critical in later age when many health-related decisions are made. Deterioration of HL has been associated with aging (see e.g., a systematic literature review by [16]), poorer health outcomes, and less frequent use of preventive services [17].

Previous studies indicate differences in individuals' HIL based on age, education, economic situation, and health status. HIL has also been positively associated with selfrated health among older people (aged 65-79) [18]. Moreover, seniors may face 
challenges in understanding the terminology used in health communication. However, research in this area especially among older people is still scarce.

A large study among American adults by Mackert et al. [19] investigated the relationship between HL and health information technology (HIT) adoption. HL was described as the Newest Vital Sign. The use of HIT tools, such as nutrition apps, activity trackers and patient portals as well as the perceived ease of use and usefulness of these applications were under scrutiny. According to the results, patients with low HL were less likely to use HIT tools or perceive them as easy or useful. To our knowledge, this is the first study to examine the relationship between HIL and opinions about and use of AMIT of older adults.

\section{Methods and Data Collection}

\subsection{Data Collection}

The study was conducted between November 2014 and January 2015 in Oulu, Finland. Oulu is Finland's fifth largest city with a population of approximately 200,000 of which 14 percent are 65 years or older [20]. The data were collected with a postal questionnaire sent to a random population-wide sample of 1,500 home dwelling individuals aged 65 or more, speaking Finnish as native language, living in Oulu area. A reminder was sent to the non-respondents four weeks after the first survey. The questionnaire was in Finnish.

The questionnaire, piloted among 11 volunteer seniors, included questions relating to several topics including health status, wellbeing, information behavior, health information literacy, use of technology, and gaming. In this study, responses on questions about EHIL and technology use were utilized. The participants were asked whether they had used a computer, tablet computer, mobile phone, or a touch screen mobile phone in the last 12 months. Moreover, they were asked whether they had Internet access at home, if they had used the Internet, had ever used the Internet with a mobile phone, and if they had ever installed an application to a mobile phone. The response alternatives were: 'Yes, and there were no major difficulties', 'Yes, but it was difficult to do', 'No', and 'I don't know'.

Questions on opinions towards mobile technology were based on the constructs of the Unified Theory of Acceptance and Use of Technology (UTAUT) [21]. The participants were instructed to give their opinion on statements related to their use of mobile information technology devices, such as smartphones or tablets. The statements were as follows: a) 'I am interested in using mobile information technologies', b) 'I believe that using mobile information technology is/would be useful in my daily life', c) 'I believe that using mobile information technology is/would be necessary in my daily life', and d) 'Using mobile information technology is easy for me'. The response alternatives were: 'Yes', 'No', and 'I don't know'.

Data on EHIL was collected with a shorter 4-item version of the EHIL screening tool [11]. The four statements are: 'I like to get health information from a variety of sources' (motivation), 'It is easy to assess the reliability of health information from the 
Internet' (evaluation), 'It is difficult to know who to believe in health issues' (confidence), and 'Terms and sentences of health information are often difficult to understand' (terminology).

The study protocol was that of the larger Gamified Services for Elderly (GASEL) project, of which the current study was a part. It was approved by the Ethics Committee of Human Sciences in the University of Oulu (statement 6/2014).

\subsection{Data Analysis}

The data were analyzed by using the software package SPSS 21 for Windows. The statistical significance of the associations between the categorical explanatory and response variables were analyzed using cross-tabulation with Pearson's chi-squared test.

An exploratory factor analysis with questions relating to use of and opinions about technology was conducted to examine the dimensional structure of the survey. The objective was to investigate whether sum variables could be used for further analysis of the data. The factor analysis showed three dimensions with four questions each. These were labeled: 1) opinions on mobile information technology, 2) mobile information technology use, and 3) "traditional" information technology use. The statements relating to each factor were further analyzed by forming sum variables. First, the statements were rated by giving one point for a 'yes' (indicating use of technology or a positive attitude towards it) response and zero points from other responses. The sum variables reflect the use of traditional technology, use of mobile technology, and opinions towards mobile information technology. The point scale is from 0 to 4 wherein 0 reflects the most negative and 4 the most positive attitude or frequency of use. Further, the sum variables were transformed into binary variables based on point counts:

- 'Traditional' information technology use: accustomed technology users (those with 4 points) and less accustomed technology users (those with 0-3 points).

- $\quad$ AMIT use: people with no experience ( 0 points) and people with at least some experience (1-4 points).

- Opinions about mobile information technology: people with negative opinions ( 0 points) and people with at least some positive opinions (1-4 points).

In the analyses, the respondents were categorized into two groups based on whether they perceived problems in the different areas of everyday health information literacy. Agreeing with the statements EHIL1 and EHIL2, and, conversely, disagreeing with the negatively worded statements EHIL3 and EHIL4 were seen as indicators of not perceiving problems in these areas.

\section{Results}

The response rate was 61.2 percent $(n=918)$. The mean age of the final study population was 73.4 (SD 6.8) and $528(57.5 \%)$ of the respondents were females. The responders were approximately 2.5 years younger than non-responders or those who were excluded $(P<.001)$, but there was no statistically significant difference in gender distribution 
$(P=.42)$.

\subsection{Everyday Health Information Literacy}

Of the respondents, 67.4 percent $(n=590)$ strongly or moderately agreed with the statement 'I like to get health information from variety of sources' (EHIL1) while 19.8 percent $(n=173)$ were unsure and 12.8 percent $(n=112)$ moderately or strongly disagreed. With the statement 'It is easy to assess the reliability of health information from the Internet' (EHIL2), 28.2 percent $(\mathrm{n}=234)$ agreed, 39.8 percent were unsure, and 32.0 percent disagreed. From the respondents, 59.8 percent $(n=526)$ agreed, 19.1 percent ( $\mathrm{n}=168)$ were unsure, and 21.0 percent $(\mathrm{n}=185)$ disagreed that 'It is difficult to know who to believe in health issues' (EHIL3). Terms and sentences of health information were considered difficult to understand (EHIL4) by 58.3 percent $(\mathrm{n}=510)$ of the respondents; 17.6 percent $(n=154)$ were unsure and 24.1 percent $(n=211)$ disagreed with this statement.

\subsection{Everyday Health Information Literacy and Use of Advanced Mobile Information Technology and Opinions Towards It}

Respondents who were confident in their abilities in evaluating online health information, determining whom to believe in health issues, and understanding health related terminology were more likely to use traditional information technologies than those who were unsure of their abilities. In other words, those who perceived problems in these areas of EHIL were more likely to get 4 points in the sum variable 'traditional' information technology use'.

Table 2. Cross-tabulations with perceived problems in everyday health information literacy and points in the 'traditional technology' use scale $(n=783)$. 


\begin{tabular}{|c|c|c|c|c|c|}
\hline & \multicolumn{5}{|c|}{$\begin{array}{l}\text { TRADITIONAL INFORMATION } \\
\text { TECHNOLOGY USE }\end{array}$} \\
\hline & & $\begin{array}{c}4 \text { points } \\
\mathrm{n}=428 \\
(54.8 \%) \\
\end{array}$ & $\begin{array}{c}<4 \text { points } \\
n=354 \\
(45.2 \%)\end{array}$ & $\begin{array}{c}\text { Total } \\
\mathrm{N}=783 \\
(100 \%)\end{array}$ & $\begin{array}{l}\text { Pearson Chi- } \\
\text { Squared }\end{array}$ \\
\hline \multirow{2}{*}{$\begin{array}{l}\text { EHIL1 } \\
\text { MOTIVATION }\end{array}$} & No problems & $296(57.6)$ & $218(42.4)$ & $514(100)$ & \multirow[b]{2}{*}{$4.73, p=.03$} \\
\hline & Problems & $133(49.4)$ & $136(50.6)$ & $269(100)$ & \\
\hline \multirow{2}{*}{$\begin{array}{l}\text { EHIL2 } \\
\text { EVALUATION }\end{array}$} & No problems & $147(69.7)$ & $64(30.3)$ & $211(100)$ & \multirow{2}{*}{$25.81, p<.001$} \\
\hline & Problems & $282(49.3)$ & $290(50.7)$ & $572(100)$ & \\
\hline \multirow{2}{*}{$\begin{array}{l}\text { EHIL3 } \\
\text { AUTHORITY }\end{array}$} & No problems & $108(65.1)$ & $58(34.9)$ & $166(100)$ & \multirow[b]{2}{*}{$33.84, p<.001$} \\
\hline & Problems & $321(52.0)$ & $296(48.0)$ & $617(100)$ & \\
\hline \multirow{2}{*}{$\begin{array}{l}\text { EHIL4 } \\
\text { TERMINOLOGY }\end{array}$} & No problems & $137(73.3)$ & $50(26.7)$ & $187(100)$ & \multirow{2}{*}{$8.97, p=.003$} \\
\hline & Problems & $292(49.0)$ & $304(51.0)$ & $596(100)$ & \\
\hline
\end{tabular}

Elderly who were confident in their abilities in evaluating online health information, determining whom to believe in health issues, and understanding health related terminology were more likely to use AMIT than those who were unsure of their abilities. In other words, those who perceived problems in these areas of EHIL were more likely to get more than 0 points for the sum variable 'mobile information technology use'.

Table 3. Cross-tabulations with perceived problems in everyday health information literacy and points in the mobile information technology use scale $(n=728)$.

\begin{tabular}{|c|c|c|c|c|c|}
\hline & \multicolumn{5}{|c|}{$\begin{array}{l}\text { MOBILE INFORMATION } \\
\text { TECHNOLOGY USE }\end{array}$} \\
\hline & & $\begin{array}{c}>0 \text { points } \\
n=307 \\
(42.2 \%)\end{array}$ & $\begin{array}{c}0 \text { points } \\
\mathrm{n}=421 \\
(57.8 \%)\end{array}$ & $\begin{array}{c}\text { Total } \\
\mathrm{N}=728 \\
(100 \%)\end{array}$ & $\begin{array}{l}\text { Pearson Chi- } \\
\text { Squared }\end{array}$ \\
\hline \multirow{2}{*}{$\begin{array}{l}\text { EHIL1 } \\
\text { MOTIVATION }\end{array}$} & No problems & $211(44.2)$ & $266(55.8)$ & 477 (100) & $2.42, p=.12$ \\
\hline & Problems & $96(38.2)$ & $155(61.8)$ & $251(100)$ & \\
\hline \multirow{2}{*}{$\begin{array}{l}\text { EHIL2 } \\
\text { EVALUATION }\end{array}$} & No problems & $94(50.5)$ & 92 (49.5) & $186(100)$ & $7.17, p=.007$ \\
\hline & Problems & $213(39.3)$ & $329(60.7)$ & $542(100)$ & \\
\hline \multirow{2}{*}{$\begin{array}{l}\text { EHIL3 } \\
\text { AUTHORITY }\end{array}$} & No problems & $86(55.1)$ & 70 (44.9) & $156(100)$ & $37.12, p<.001$ \\
\hline & Problems & 221 (38.6) & 351 (61.4) & $572(100)$ & \\
\hline \multirow{2}{*}{$\begin{array}{l}\text { EHIL4 } \\
\text { TERMINOLOGY }\end{array}$} & No problems & $108(62.1)$ & $66(37.9)$ & $174(100)$ & $13.67, p<.001$ \\
\hline & Problems & 199 (35.9) & 355 (64.1) & 554 (100) & \\
\hline
\end{tabular}

All dimensions of EHIL were linked to opinions towards AMIT. Respondents who did not perceive problems in EHIL were more likely to receive more than 0 points for the sum variable of 'opinions about mobile information technology'. Therefore, for example, those with the most negative opinions about mobile information technology were more likely to think that it is not easy to assess the reliability of health information 
obtained from the Internet $\left(\chi^{2}(1)=11.680, p=0.001\right)$ and that health related terminology and statements are often difficult to understand $\left(\chi^{2}(1)=28.095, \mathrm{p}<0.001\right)$ (See Table 4).

Table 4. Cross-tabulations with perceived problems in everyday health information literacy and points in opinions about mobile information technology scale.

\begin{tabular}{|c|c|c|c|c|c|}
\hline & & \multicolumn{4}{|c|}{$\begin{array}{l}\text { OPINIONS ABOUT MOBILE } \\
\text { INFORMATION TECHNOLOGY }\end{array}$} \\
\hline & & $\begin{array}{l}>0 \text { points } \\
\mathrm{n}=376 \\
(49.6 \%)\end{array}$ & $\begin{array}{l}0 \text { points } \\
\mathrm{n}=382 \\
(50.4 \%)\end{array}$ & $\begin{array}{l}\text { Total } \\
\mathrm{N}=758 \\
(100 \%)\end{array}$ & $\begin{array}{l}\text { Pearson } \\
\text { Squared }\end{array}$ \\
\hline \multirow{2}{*}{$\begin{array}{l}\text { EHIL1 } \\
\text { MOTIVATION }\end{array}$} & No problems & $269(54.1)$ & $228(45.9)$ & $497(100)$ & $11.80, p<.001$ \\
\hline & Problems & $107(41.4)$ & $154(59.0)$ & $261(100)$ & \\
\hline \multirow{2}{*}{$\begin{array}{l}\text { EHIL2 } \\
\text { EVALUATION }\end{array}$} & No problems & $121(59.9)$ & $81(40.1)$ & $202(100)$ & $11.68, p=.001$ \\
\hline & Problems & 255 (45.9) & $301(54.1)$ & $556(100)$ & \\
\hline \multirow{2}{*}{$\begin{array}{l}\text { EHIL3 } \\
\text { AUTHORITY }\end{array}$} & No problems & $96(60.8)$ & $62(39.2)$ & $158(100)$ & 9.94, p<.002 \\
\hline & Problems & $280(46.7)$ & $320(53.3)$ & $600(100)$ & \\
\hline \multirow{2}{*}{$\begin{array}{l}\text { EHIL4 } \\
\text { TERMINOLOGY }\end{array}$} & No problems & $122(66.7)$ & $61(33.3)$ & $183(100)$ & $28.10, p<.001$ \\
\hline & Problems & $254(44.2)$ & $321(55.8)$ & $575(100)$ & \\
\hline
\end{tabular}

\section{$5 \quad$ Discussion and Conclusions}

Older people are rather motivated to seek health information but face difficulties in assessing the reliability of information from online sources and understanding health terminology. Many also find it difficult to know whom to believe on health issues.

More than half of the respondents had used a computer, a mobile phone, had an Internet connection at home, and had used the Internet during the previous year. It should be noted, however, that although Finnish elderly people are relatively techsavvy, a large proportion of older people still do not use these information technologies. As can be expected, AMIT use is less common among older people: almost 60 percent of the respondents had not yet used tablet computers or touch screen phones. However, approximately half of the respondents had at least some positive opinions about mobile information technology in that they were interested in it, considered it beneficial, necessary, or easy to use.

Based on our results, the users of both traditional and mobile information technology differ from non-users in that they are more confident in their abilities in evaluating online health information, determining who to believe in health issues, and understanding health related terminology. Also, positive opinions towards mobile information technology were linked to perceiving fewer problems in the areas of EHIL.

Mackert et al. [19] showed that people with low HL were less likely to use HIT tools or perceive them as easy and useful. Our study indicates that perceived problems in HIL 
are also linked to technology use. Furthermore, the literature on the "gray" digital divide considers lack of use as a key reason for the digital divide for older adults (second level digital divide) [8]. According to our results, those in danger of marginalization from the use of AMIT and mobile e-services offered also have difficulties in evaluating and understanding health information.

The strength of this study is the large random population-based sample with a high response rate. Both genders and different age groups of seniors were reached. However, the results reported are based on small number of self-evaluation questions. Even though self-evaluation is a common way to measure HIL and HL, there is an ongoing debate on whether HL represents a skill-based construct or if it more broadly captures personal activation or motivation to manage health [22]. In general, the EHIL screening tool may reflect confidence and motivation rather than actual skills. Furthermore, the analysis did not take into account for confounding factors that may influence both EHIL and AMIT. However, we did not study causal relationships but associations between the variables.

The differences found in this study concerning older adults EHIL skills and use and opinions should be taken into account when designing HIL promotion, targeted and tailored health communication strategies, and intervention studies. Because of this, future EHIL studies should focus on the different aspects of EHIL, for example on skills and abilities to use health information. In addition, older adults with different levels of EHIL and utilization rate of AMIT should be included in designing e-health services targeted for this specific age group. Since older people are at risk of marginalization in regard to m-services, these results should be utilized by decision-makers and software designers in digitalization of services for older people for example through tailoring health contents in these services to better match the users' competencies and preferences.

\section{Acknowledgements}

GASEL study has received financial support from the Finnish Funding Agency for Innovation (TEKES). The researchers of Åbo Akademi are part of the HIBA project that is being funded by Academy of Finland.

\section{References}

1. Mockford, C., Staniszewska, S., Griffiths, F., Herron-Marx, S.: The impact of patient and public involvement on UK NHS health care: a systematic review. Int. J. Qual. Health Care 24(1), 28-38 (2012)

2. Venkata, R.S., Yun-Ke, C., Shaheen, M., Schubert, F.: Health information literacy of senior citizens - a review. In: S. Kurbanoğlu et al. (Eds.): ECIL 2014, CCIS 492, pp. 128 137. Springer. (2014)

3. Enwald, H., Kangas, M., Keränen, N., Immonen, M., Similä, H., Jämsä, T., Korpelainen, R.: Health information behaviour, attitudes towards health information and motivating factors for encouraging physical activity among older people: differences by sex and age 
In Proceedings of ISIC, Zadar, Croatia, 20-23 September, 2016: Part 2. Information Research, 22 (1), paper isic1623. http: //www. informationr. net/ir/221/isic/isic1623.html (2017)

4. Keränen, N., Kangas, M., Immonen, M., Similä, H., Enwald, H., Korpelainen, R., Jämsä, T.: Use of Information and Communication Technologies Among Older People With and Without Frailty: A Population-Based Survey. J. Med. Intern. Res. 19(2).

http: //www.jmir.org/2017/2/e29/ (2017)

5. Enwald, H., Kangas, M., Keränen, N., Korpelainen, R, Huvila, I., Jämsä, T.: Opinions and Use of Mobile Information Technology Among Older People in Northern Finland Preliminary Results of Population Based Study. Proceedings of the Annual meeting of the Association for Information Science and Technology, vol 53. 79th ASIS\&T annual meeting Oct 14-18, 2016, Copenhagen, Denmark. (2016)

6. Niehaves, B., Plattfaut, R.: Internet adoption by the elderly: employing IS technology acceptance theories for understanding the age-related digital divide. Eur. J. Inf. Sys. 23(6), 708-726 (2014)

7. Council of European Union: More accessible websites across Europe: agreement with European Parliament. Press release.

http://www. consilium.europa.eu/en/press/press-

releases/2016/05/03-more-accessible-website-across-europa/ (2016)

8. Hill, R., Betts, L.R., \& Gardner, S.E.: Older adults experiences and perceptions of digital technology: (Dis)empowerment, wellbeing, and inclusion.Comput. Hum. Beh. 48(Issue C), 415-423 (2015)

9. Heart. T., Kalderon, E.: Older adults: Are they ready to adopt health-related ICT? Int. J. Med. Inform. 82, e209-e231 (2013)

10. Statistics Finland: Finnish residents use the Internet more and more often. Helsinki: Statistics Finland.

http://www.stat.fi/til/sutivi/2016/sutivi_2016_2016-1209 tie 001 en.html (2016)

11. Niemelä, R., Ek, S., Eriksson-Backa, K., Huotari, M-L.: A screening tool for assessing everyday health information literacy. Libri, 62(2), 125-134 (2012)

12. Shipman, J.P., Kurtz-Rossi, S., Funk, C.J.: The health information literacy research project. J. Med. Libr. Assoc. 97(4), 293-301 (2009)

13. Hirvonen, N., Ek, S., Niemelä, R., Korpelainen, R., Huotari, M.L.: Socio-demographic characteristics associated with the everyday health information literacy of young men. Proceedings of ISIC, the Information Behaviour Conference, Leeds, 2-5 September, 2014: Part 2. Information Research, 20(1), paper isic25. http://www. informationr. net/ir/201/isic2/isic25.html\#.VSeH3 fmUd1Y (2015)

14. Enwald, H., Hirvonen, N., Huotari, M.L., Korpelainen, R., Pyky, R., Savolainen, M., Salonurmi, T., Keränen, A.M., Jokelainen, T., Niemelä, R.: Everyday health information literacy among young men compared with adults with high risk for metabolic syndrome a cross-sectional population-based study. J. Inf. Sc. 42(3), 344-355. (Special Issue of I3 Conference, at Aberdeen, UK, June 2015) (2016)

15. Hirvonen, N., Enwald, H., Nengomasha, C., Abankwah, R., Uutoni W. U., Korpelainen, R., Pyky, R., Huotari, M.-L., Mayer, A.-K.: Validating the factorial structure of the everyday health information literacy screening tool in three different populations. Proceedings of ISIC: the Information Behaviour Conference. Extended abstract for a poster (2016) 
16. Zamora, H., Clingerman, E.M. Health literacy among older adults: A systematic literature review. J. Gerontol. Nurs. 37(10), 41-51 (2011)

17. Berkman, N.D., Sheridan, S.L., Donahue, K.E., Halpern, D.J., Crotty, K.: Low health literacy and health outcomes: an updated systematic review. Ann. Intern. Med. 155(2), 97-107 (2011)

18. Eriksson-Backa, K., Ek, S., Niemelä, R., Huotari, M.L.: Health information literacy in everyday life: A study of Finns aged 65-79 years. Health Informatics J. 18(2), 83-94 (2012)

19. Mackert, M., Mabry-Flynn, A., Champlin, S., Donovan, E.E., Pounders, K. Health Literacy and Health Information Technology Adoption: The Potential for a New Digital Divide. J. Med. Internet Res. 18(10), e264. https://www.jmir.org/2016/10/e264 (2016)

20. Pxnet2.stat: Väestöllisiä tunnuslukuja alueittain (in Finnish) http://pxnet2.stat.fi/PXWeb/pxweb/fi/StatFin/StatFin vrm aerak/048_vaerak_tau_203.px(2013)

21. Venkatesh, V., Morris, M., Gordon, B., Davis, F.D.: User acceptance of information technology: toward a unified view. MIS Q Sep 27(3), 425-478 (2003)

22. Smith, S.G., Curtis, L.M., Wardle, J., von Wagner, C., Wolf, M.S.: Skill set or mind set? Associations between health literacy, patient activation and health. Plos One 8(9), 374373.

http://journals.plos.org/plosone/article?id=10.1371/journal. pone.0074373(2013) 